\title{
Acerca de la 'realidad': una mirada desde Asia
}

institucionales.us.es/ambitos/

\author{
Hui Feng Liu \\ Universidad Wenzao, Kaohsiung (Taiwán) \\ vanesaliu@yahoo.com
}

English Version: About 'reality': a look from Asia

Después de constatar -teórica y empíricamente- la calculada intencionalidad de algunos mensajes periodísticos, la autora centra su análisis en casos de tergiversación informativa: el llamado problema catalán, en España, visto desde la televisión taiwanesa, la parcialidad del tratamiento con el que determinado periodismo aborda la figura del presidente de Estados Unidos, Donald Trump, y la superficialidad y descontextualización que también ha utilizado el mensaje periodístico occidental en

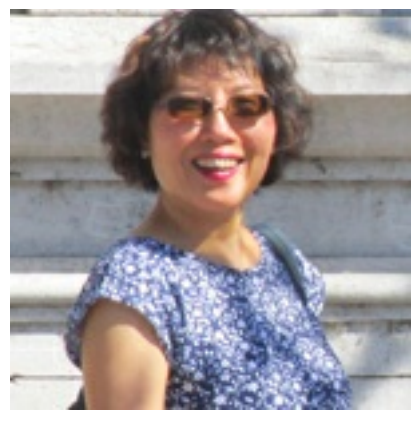
relación con las elecciones presidenciales de 2016 en Taiwán.

Palabras clave: periodismo, mensaje, desinformación, simplicidad, descontextualización.

Abstract: After confirming - theoretically and empirically - the calculated intentionality of some journalistic messages, the author focuses her analysis on cases of informational misrepresentation: the so-called Catalan problem, in Spain, seen from Taiwanese television, the partiality of the treatment with which determined journalism It deals with the figure of the president of the United States, Donald Trump, and the superficiality and decontextualization that the western journalistic message has also used in relation to the presidential elections of 2016 in Taiwan.

Keywords: journalism, message, misinformation, simplicity, decontextualization.

\section{Introducción}

El tratamiento realizado por los medios informativos taiwaneses y de muchos países del planeta tiende a simplificar, descontextualizar y politizar la realidad presentada y, como consecuencia, se fomenta un nivel de desconocimiento en aumento en la percepción de los espectadores y lectores, quienes pueden llegar a formular conclusiones superficiales o erróneas a partir de su incesante contacto con los mensajes defectuosos. Dichos medios ofrecen la actualidad con juicios de valor y términos concluyentes que desde el punto de vista periodístico no están siendo justificados.

A nuestro parecer, es más que sorprendente la elevada presencia indebida de las críticas de los medios informativos mundiales en la cobertura de los hechos espinosos y delicados. Coincidiendo con la manera de pensar de Carlos Ruiz, los medios de comunicación, en lugar de defender los intereses públicos, "actúan ejerciendo una censura privada y ocultan mostrando el rostro más favorable del actor político o económico" [1]. 
Existen numerosos ejemplos para ilustrar lo dicho, entre los cuales se encuentran los casos del desafío independentista de Cataluña, de las elecciones presidenciales de Taiwán en 2016 y de las medidas y perfil del presidente estadounidense Donald Trump.

\section{El caso de Cataluña}

En referencia al caso de Cataluña, los medios mundiales están muy pendientes de las acciones del expresidente del Generalitat, Carles Puigdemont, y de los partidos catalanes independentistas. Cuando se celebró el referendúm el 1 de octubre de 2017, ese día los informativos de Taiwán se hicieron también eco de este suceso. Cuando la policía local tuvo que desalojar, bajo la orden del estado español, a la fuerza a los votantes independentistas en los colegios electorales, el enfoque principal de una de las principales cadenas taiwanesas, FTV, se centró en la controvertida actuación policial con sus forcejeos y golpes a los que insistían en quedarse, sin dar ningún detalle sobre el porqué del operativo policial.

En otra fecha posterior, esta misma cadena llegó incluso a señalar que «Cataluña sufre de la opresión del Estado español desde siempre», en un reportaje donde no se encontraba suficiente información contextual para comprender en profundidad y con objetividad el origen del problema y las posturas del gobierno catalán y del español. Así como el caso de las dos informaciones mencionadas con anterioridad, en varias ocasiones FTV emitió varias noticias que contenían una relevante dosis de connotaciones subjetivas, sin basarse en un amplio bagaje histórico, político y social y sin explicar el significado de la aplicación del artículo 155 de la Constitución Española. Por ello quedó claramente patente el hecho de una simplificación en la contextualización del acontecimiento. Entonces surge la pregunta: ¿se trata simplemente de fallos metodológicos o de un acto de manipulación consciente?

Para responder a esta pregunta, quizás deberíamos fijarnos en el aspecto ideológico del medio, y en el caso de la cadena citada se trata justamente de un canal informativo que siempre ha dado su apoyo, implícita y explícitamente, a la idea de la independencia de Taiwán. En cuanto a esta conducta periodística, quizás la podemos comprender mejor a través de las palabras de Ignacio Muro Benayas: "Los acontecimientos dominantes son, simplemente, los que interesan al poder dominante en cada momento" [2].

\section{El caso Donald Trump}

Otro fenómeno que nos inspira a reflexionar sobre la conducta periodística de los medios informativos en el presente es la actitud excesivamente hostil del mundo mediático hacia Donald Trump, manifestada a través de una frecuencia abusiva de términos negativos sobre sus creencias y figura personal. Hablando del actual presidente estadounidense, desde el primer instante en que decidió representar al Partido Republicano, para competir en la carrera presidencial con su principal contrincante Hillary Clinton, la gran mayoría de los medios de comunicación de todo el mundo no han dejado de darle la espalda en todo momento. Y esta actitud aún insistía incluso después de la investidura del republicano, sin cambios sustanciales.

Coincidiendo en este sentido, la prensa española también actúa de manera similar mediante juicios de valor negativos que podrían terminar orientando a los lectores a 
asociar Trump con un político ineficaz. Si aludimos al caso del rotativo El País, el actual presidente estadounidense es, en palabras de los columnistas de este diario, un "político tóxico" [3]; una "basura" [4]; una "bestia" [5]; "la criatura del Doctor Frankenstein" [6]; un "idiota" [7]; entre otros.

Por fortuna, pese al predominio de los mensajes unilaterales, de vez en cuando podemos encontrarnos con voces opuestas, como la de criticar la falta de objetividad en los puntos de vista de los periodistas. Como ejemplo, el tratamiento del caso de "la desaparición de las páginas en español de la Casa Blanca" poco después de la investidura. Dicha "desaparición" levantó inmediatamente mucha indignación en España, pero poco después se comprobó que sólo se trataba de un rumor, puesto que la página había sido cerrada temporalmente a causa de una restauración. La indignación, desde el punto de vista del columnista de $A B C$ Hermann Tertsch, "resultó gratuita porque la información sobre Washington era falsa" [8]. De nuevo nos surge una pregunta: ¿cómo es posible que cuando hay tanta diversidad de medios informativos hoy en día casi todos pensamos de manera parecida?

Respecto a la relación conflictiva entre Trump y los medios de comunicación, en realidad se podría decir que no siempre ha sido mala. Mientras desempeñaba meramente su rol de un exitoso empresario, la relación que mantenían ambas partes era más bien armoniosa. No obstante, este clima ha dado un giro desde que se lanzó al mundo político: al parecer, ahora, como político, Trump no encuentra la forma de convencer al mundo de que puede gobernar con capacidad Estados Unidos aún siendo un presidente sin ninguna experiencia en la política, de demostrar que un magnate puede ser también un buen presidente.

Uno de los casos que ha ocasionado un delirio masivo en el contexto mediático respecto a Trump es la construcción del muro en la frontera con México. En todo momento se percibía que la imagen de Trump transmitida por muchos medios correspondía más bien a la de un canalla y que había casi una nula presencia de comentarios acerca de las razones o del otro porqué de la decisión de Trump: en realidad lo que iba a hacer Trump era seguir completando la parte que faltaba del muro, es decir, hasta entonces había una parte del muro que ya estaba construida bajo el mandato de Bill Clinton hace más de veinte años.

\section{Elecciones presidenciales de Taiwán en 2016}

Para ir finalizando, me gustaría comentar acerca del discutible despliegue informativo de las elecciones presidenciales de Taiwán en 2016, realizado por los relevantes medios internacionales. En las informaciones emitidas por éstos mismos se detecta una visible existencia de atribuciones simplistas. Con un significativo volumen de connotaciones subjetivas, dichas informaciones tenían el foco puesto principalmente en el aspecto político y menos en otras cuestiones del contexto social taiwanés que merecían ser desarrolladas también, como la disminución de oportunidades laborales o la subida del coste de la vida, entre otras. Diferentes medios mundiales como ABC (España), El Mundo (España), El País (España), LaVanguardia (España), CNN Español (Estados Unidos), BBC Mundo (Inglaterra), Clarín (Argentina), Excelsior (México), en términos generales, durante el periodo de las elecciones carecieron de un desarrollo contextual sólido social que era absolutamente necesario para comprender lo que estaba ocurriendo, y en especial para todo lo relacionado con la compleja relación entre China y Taiwán. 
Pues bien, excepto la alusión a la conocida reivindicación nacionalista de Taiwán ante China, otras cuestiones valoradas con preocupación por el electorado taiwanés tuvieron una presencia claramente secundaria en las páginas web de dichos medios. Así, una información cuando es incompleta puede correr el riesgo de convertirse en propaganda, en lugar de ser un servicio de interés social. "Una información que es amputada, manipulada o suprimida para ocultar o esconder no es información, sino propaganda" [9], comenta Carlos Ruiz.

Como expresa María Mercedes Zamarra López, en España "el cuarteto de principales medios impresos generalistas lo conforman los diarios: El País, El Mundo, ABC y La Razón" [10]. En los textos de estos diarios españoles una vez examinados, se observa con claridad que la protagonista principal es China y a su favor va la información aunque con marcados matices críticos hacia su gobierno por parte de los medios menos identificados con su ideología. Bajo el titulillo "Foco internacional", el diario La Vanguardia señala que "las elecciones son seguidas de cerca tanto por China como Estados Unidos por la importancia de sus relaciones bilaterales". Y esta especial atención por parte del primer país se debe a que éste "ejerce un activo control sobre la economía y la política taiwanesa" [11]. Al respecto, se trata de una declaración parcialmente correcta, puesto que Taiwán tiene absoluta libertad para desarrollar su economía, sin la mínima intervención de China en el ámbito económico.

Coincidiendo con La Vanguardia, en ese carácter dominante de China, El País señala ese aspecto pero se permite introducir una crítica por la ausencia de libertades en la política china (que se abre a otro enfoque) con estos términos: "Al contrario que en la China Continental, donde es difícil saber cómo se mueven los hilos del poder y la censura campa a sus anchas en la red de redes, Taiwán (República de China), el país que el gigante asiático reclama como una de sus provincias, hace gala de sus libertades a través de Internet" [12]. Fieles al auténtico enfoque, desde el rotativo mexicano Excelsior, China es presentada como un país que "podría utilizar la presión diplomática y económica si ve que [la candidata a la presidencia taiwanesa Tsai] se aleja demasiado de su visión de unificación" [13].

Sabemos que al considerar a Taiwán como una de sus provincias, China no va a permitir nunca que Taiwán se independice. En este sentido, El País informa ante las elecciones que Pekin "exige que el ganador de los comicios del sábado acepte el llamado "consenso del 92", el principio de que hay "una sola China". Aunque con una interpretación completamente distinta de la de Pekín, el KMT [14] sí reconoce esa premisa" [15]. Se considera que si Taiwán se separa oficialmente, China sería capaz de acudir a la fuerza si es necesario para defender su terroritio. De este modo constata CNN en Español que: "China tiene misiles apuntando a la isla" ${ }^{[16]}$. $A B C$ certifica lo mismo que CNN: "Con su previsible victoria, los electores castigarán así al KMT por estrechar relaciones con China, que considera a Taiwán una "provincia rebelde" y ha prometido unificarla al resto del país, incluso por la fuerza si llega a declarar formalmente su independencia” [17]. Así, también, para El Mundo, "los líderes comunistas chinos observan a la futura presidenta con enorme desconfianza" [18].

A pesar de todo, los mensajes de los medios mencionados favorecían, desde el punto de vista connotativo, la construcción de una imagen positiva de la presidenta electa Tsai Ing- 
wen, así como el hecho de destacar su ideología independentista, una actitud mediática que no concordaba plenamente con su discreta forma de ser que incluye manifestar su ideología con discreción. En la actualidad, ahora, más bien, Tsai desea establecer una relación sin tensiones con China Continental y ha prometido incluso en un determinado momento no hacer declaración de independencia.

A modo de reflejar lo que acabamos de plantear, a continuación, vamos a seleccionar unas declaraciones vertidas en la prensa mundial en español al ganar las elecciones Tsai:

"Taiwán ha elegido a la candidata del independentista Partido Demócrata Progresista(...)" [19] $(A B C)$; "La candidata independentista logra superar el umbral de votos para convertirse en la mandataria (...)" [20] (El Mundo); "Con una inteligencia que destacan todos cuantos la conocen (...)" [21] (El País); "Tsai, del independentista Partido Demócrata Progresista (PDP), obtuvo el 56,2\% de los votos (...)" [22] (Clarín).

\section{Conclusión}

新聞媒體的職責本應客觀報導, 並提供多元的內容及多元的資料來源, 不幸的是偏頗的報導 及帶有政治色彩的內容隨時可見。雖然在世界各大新聞報紙及電子媒體也會發生這個情況， 但依個人所見, 這個現象在台灣更加明顯, 更令人注意的是當地的新聞媒體選邊站的行為竟 是持一個不算低調的態度，透過帶有意識型態的新聞報導他們高頻率地為所支持的政黨發聲， 行為如同政黨的發言人。

(Una de las responsabilidades de los medios de comunicación consiste en informar objetivamente a los receptores de sus mensajes y proporcionar una amplia gama de contenido y diversidad de fuentes de información. Desafortunadamente, la presencia del tratamiento tendencioso y del contenido cargado indebidamente de mensajes políticos es cada vez más habitual. Aunque esto puede suceder en los principales periódicos y medios electrónicos del mundo, como la mayoría de los ejemplos elegidos en esta exposición; en nuestro parecer este fenómeno es aún más notorio en Taiwán, cuyos medios actúan casi sin escrúpulos como si fueran portavoces de los partidos políticos.)

\section{Bibliografía y materiales periodísticos consultados}

AZÚA, Félix de: "El huevo”, en El País, 24-I-2017.

DPA: “Tsai Ing-wen, la 'Markel de Asia”, en El Mundo, 16 I-2016.

Efe: "Taiwán elige a la independentista Tsai Ing-Wen como primera presidenta en la historia del país", en ABC, 16-I-2016.

GARCÍA, Daniel: "Internet, el otro campo de batalla en los comicios taiwaneses", en El País, 14-I-2016.

GRANDES, Almudena: “Frankenstein”, en El País, 30-I-2017.

HUNT, Katie / Lu Stout, Kristie: "Taiwán tundra una presidenta por primera vez en su historia”, en CNN en Español, 16 I-2016.

2016. DÍEZ, Pablo: "La independentista Tsai Ing-wen, favorita en las presidenciales de Taiwán”, en ABC, 16 I-2016. 
MILLAS, Juan José: “El informe”, en El País, 21-X-2016.

MURO BENAYAS, Ignacio. Globalización de la información y agencias de noticias. Entre el negocio y el interés general, Paidós, Barcelona, 2006.

ESPINOSA, Javier: “Tsai Ing-Wen, elegida primera presidenta de Taiwan”, en El Mundo, 16-I-2016.

RUIZ, Carlos. La agonía del cuarto poder. Prensa contra democracia, (EX) tensiones, Barcelona, 2008.

TERTSCH, Hermann: “De muros, ridículos y delirios”, en ABC, 28-I-2017.

VIDAL LIY, Macarena: "Las elecciones en Taiwán ponen a prueba el deshielo con China", en El País, 14-I-2016.

VIDAL LIY, Macarena: "Tsai Ing-wen, la mujer que abre una nueva era en Taiwán”, en El País, 15-I-2016.

VINCENT, Manuel: "Borrascas”, en El País, 22-I-2017.

VICENT, Manuel: “Todo encaja”, en El País, 13-XI-2016.

ZAMARRA LÓPEZ, María Mercedes: "Análisis de los diarios digitales españoles más influyentes y su presencia en las redes sociales", en Estudios sobre el Mensaje Periodístico, Vol. 21, Núm. 1, Universidad Complutense, servicio de publicaciones, Madrid, 2015.

[1] RUIZ, Carlos:La agonía del cuarto poder. Prensa contra democracia, (EX) tensiones, Barcelona, 2008, p. 344.

[2] MURO BENAYAS, Ignacio:Globalización de la información y agencias de noticias. Entre el negocio y el interés general, Paidós, Barcelona, 2006, p. 27.

[3] VINCENT, Manuel: "Borrascas", en El País, 22-I-2017.

[4] VICENT, Manuel: "Todo encaja”, en El País, 13-XI-2016.

[5] AZÚA, Félix de: "El huevo", en El País, 24-I-2017.

[6] GRANDES, Almudena: “Frankenstein”, en El País, 30-I-2017.

[7] MILLAS, Juan José: “El informe”, en El País, 21-X-2016.

[8] TERTSCH, Hermann: "De muros, ridículos y delirios", en ABC, 28-I-2017.

${ }^{[9]}$ RUIZ CARLOS. Op.cit.

[10] ZAMARRA LÓPEZ, María Mercedes: "Análisis de los diarios digitales españoles más influyentes y su presencia en las redes sociales", en Estudios sobre el Mensaje Periodístico, Vol. 21, Núm. 1, Universidad Complutense, servicio de publicaciones, Madrid, 
2015, p. 157.

[11] Redacción/Agencias: "Los independentistas se imponen en las elecciones de Taiwán", en La Vanguardia, 16-I-2016.

[12] GARCÍA, Daniel: "Internet, el otro campo de batalla en los comicios taiwaneses", en El País, 14-I-2016.

[13] Redacción: "Taiwán elige a la primera presidenta en su historia", en Excelsior, 17-I2016.

[14] KMT es la abreviatura del partido Kuo Min Tang (Partido Nacionalista Chino), una de las dos principales fuerzas políticas en Taiwán. Es un partido que busca mantener buena relación entre China y Taiwán, y que reconoce que Taiwán forma parte del territorio de China.

[15] VIDAL LIY, Macarena: "Las elecciones en Taiwán ponen a prueba el deshielo con China”, en El País, 14-I-2016.

[16] HUNT, Katie / LU STOUT, Kristie: "Taiwán tundra una presidenta por primera vez en su historia", en CNN en Español, 16 I-2016.

${ }^{[17]}$ M. DÍEZ, Pablo: "La independentista Tsai Ing-wen, favorita en las presidenciales de Taiwán”, en ABC, 16 I-2016.

[18] DPA: "Tsai Ing-wen, la 'Markel de Asia”", en El Mundo, 16 I-2016.

[19] Efe: "Taiwán elige a la independentista Tsai Ing-Wen como primera presidenta en la historia del país", en ABC, 16-I-2016.

[20] ESPINOSA, Javier: "Tsai Ing-Wen, elegida primera presidenta de Taiwan", en El Mundo, 16-I-2016.

[21] VIDAL LIY, Macarena: "Tsai Ing-wen, la mujer que abre una nueva era en Taiwán", en El País, 15-I-2016.

[22] Redacción: “Por primera vez, una mujer será presidenta de Taiwán”, en Clarín, 16-I2016.

\section{BREVE SEMBLANZA DE LA AUTORA:}

Hui Feng Liu es Doctora en Periodismo por la Universidad de Sevilla. En 2009 defendió la tesis doctoral titulada "Estados Unidos a través de los mensajes periodísticos de El País Y El Mundo: desde la primera elección de George W. Bush hasta las reacciones tras el ataque a las Torres Gemelas y al Pentágono (octubre de 2000-septiembre de 2001)". Actualmente es Profesora a tiempo completo en el Departamento de Español de la Universidad Wenzao, Kaohsiung (Taiwán R.O.C.) 
- Recibido: 05/03/2018

- Aceptado: 15/03/2018

Ámbitos. Revista Internacional de Comunicación, n.40, edición de primavera, 2018. 